\title{
Challenges in a the management of adrenal Cushing's syndrome associated with bilateral adrenal tumours and uterine leiomyoma
}

Authors C.Poiana, M.Carsote, A.Gruia, D.Peretianu, E.Gheorghiu, R.Petris, S.Paun, A.Dumitrascu, D.Hortopan

Hospital: "C.Davila" University of Medicine and Pharmacy, Bucharest, Romania; “C.I.Parhon” National Institute of Endocrinology, Bucharest, Romania; "Medlife" Medical Centre, Bucharest, Romania; "SCM Povernei" Medical Centre, Bucharest, Romania "Floreasca" Emergency Hospital, Bucharest, Romania

\section{Objectives:}

The Cushing's syndrome associated bilateral adrenal tumours comprise a wide area of diagnosis.

The therapeutic approach is challenging since unilateral intervention might involve persistent hypercotisolemia, and bilateral adrenalectomy induces chronic adrenal insufficiency.

The adrenal vein catheterise is not available in many countries.

\section{Methods:}

This is a case report presentation.

\section{Results:}

50-year old non-smoker female has the following medical history: 2 years ago she presented to endocrinology because of weight gain with android features.

On admission, diabetes mellitus and high cholesterol were found.

The plasma ACTH was low (of $3 \mathrm{pg} / \mathrm{mL}$ ), and the $2 \mathrm{mg}$ of 2 days dexametasone suppression test showed no suppression of plasma morning cortisol.

The computed tomography showed a right adrenal tumour of maximum $3 \mathrm{~cm}$ diameter and a smaller left adrenal tumour. Laparoscopic right adrenalectomy was performed. After surgery, no sign of adrenal insufficiency was found, so no glucocorticoid substitution was necessary.

The blood levels remained normal. Six months after surgery, the morning plasma cortisol after $2 \mathrm{mg}$ or 2 days dexametasone was $1.13 \mu \mathrm{g} / \mathrm{dL}$. After six more months, the patient accused asthenia, and presented hemorrhagic diathesis as skin bruising, and three episodes of menopausal methrorrhagia.

Also, the Cushing syndrome was suspected, the adrenal axes remained normal (morning cortisol of $11.9 \mu \mathrm{g} / \mathrm{dL}, \mathrm{ACTH}$ of 7 $\mathrm{pg} / \mathrm{mL}$ ) but the left adrenal tumour increased at $4 \mathrm{~cm}$ maximum diameter; the pelvic ultrasound revealed an uterine leiomyoma of $2.82 \mathrm{~cm}$. Endometrial haemostasis was performed by biopsy.

18 months after surgery the patient felt well, and the dexamethasone suppression test was still normal. Close follow-up is necessary.

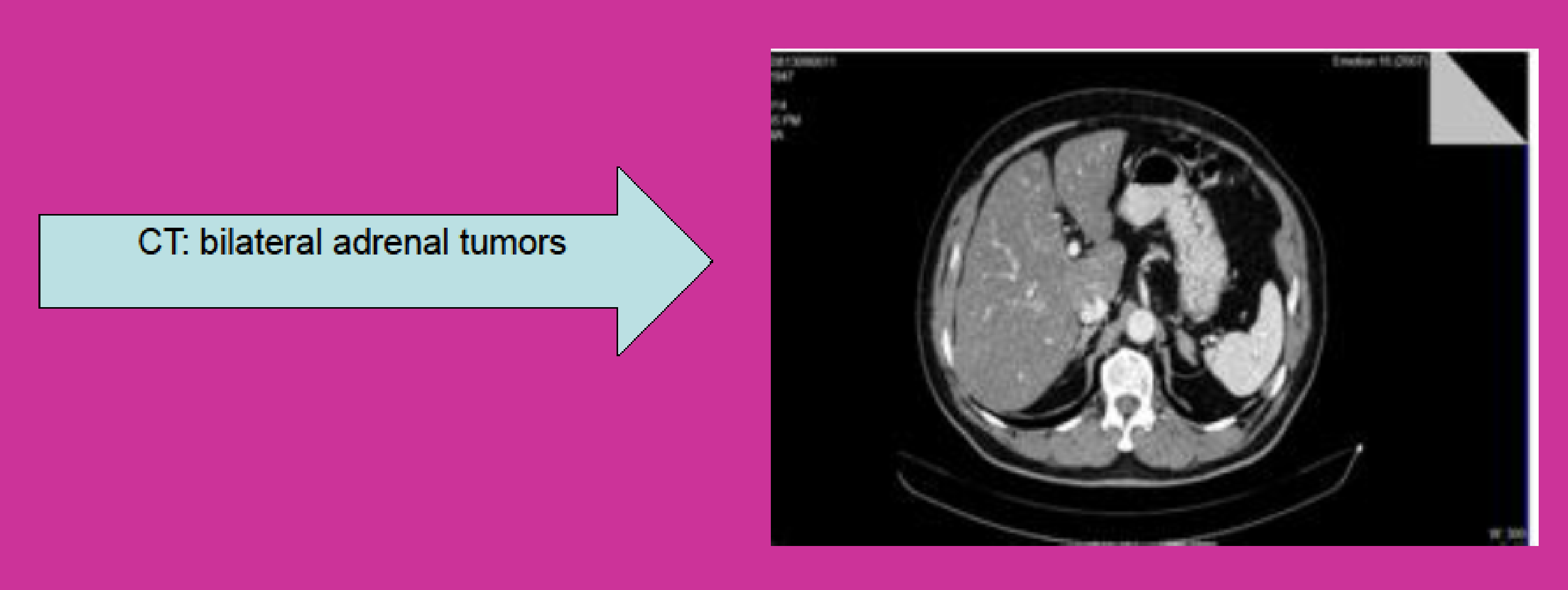

\section{Conclusions:}

Unilateral adrenalectomy in the bilateral adrenal tumours underling Cushing's syndrome may involve the syndrome remission but life follow-up is necessary because the risk of syndrome relapsing (in case of bilateral macronodular hyperplasia); the lack of adrenal insufficiency after first intervention is the marker of bilateral involvement.

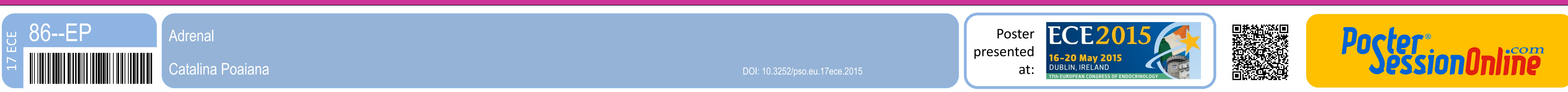

